\title{
Youth Initiated Mentoring: Investigating a New Approach to Working with Vulnerable Adolescents
}

\author{
Sarah E. O. Schwartz · Jean E. Rhodes • \\ Renée Spencer · Jean B. Grossman
}

Published online: 19 June 2013

(C) Society for Community Research and Action 2013

\begin{abstract}
This study examines youth initiated mentoring (YIM), a new approach to mentoring in which youth nominate mentors from among the non-parental adults within their existing social networks (e.g., teachers, family friends, extended family members). YIM is currently being implemented through the National Guard Youth ChalleNGe Program (NGYCP), an intensive residential intervention program for youth ages 16-18 who have dropped out or been expelled from high school. This study employed a mixed methods explanatory design, drawing on quantitative data from a national longitudinal evaluation of $\operatorname{NGYCP}(N=1,173)$ and qualitative data from a subsample of participants $(N=30)$ in the evaluation. Results indicated that more enduring mentoring relationships were associated with increased retention of educational, vocational, and behavioral outcomes 3 years following entry into the study. Qualitative data suggested that, when relationships endured, mentors contributed to improvements in participants' educational and occupational success, quality
\end{abstract}

S. E. O. Schwartz $(\bowtie) \cdot$ J. E. Rhodes

Department of Psychology, University of Massachusetts Boston, 100 Morrissey Blvd., Boston, MA 02125, USA

e-mail: sarah.schwartz001@umb.edu

J. E. Rhodes

e-mail: jean.rhodes@umb.edu

R. Spencer

School of Social Work, Boston University, 264 Bay State Rd., Boston, MA 02215, USA

e-mail: rspenc@bu.edu

\section{J. B. Grossman}

Woodrow Wilson School of Public and International Affairs, Princeton University, Princeton, NJ 08544, USA

e-mail: jgrossma@princeton.edu of relationships with parents, peers, and others, and selfconcept by providing social-emotional support, instrumental support, and guidance. Results also revealed that relationships were more likely to endure when youth chose their mentors on their own (rather than receiving help from parents or program staff) and when mentors were of the same race as youth. Implications for research and practice are discussed.

Keywords Mentoring $\cdot$ Adolescents $\cdot$ Dropouts $\cdot$ Mixed methods

\section{Introduction}

As many as 6 million young people between the ages of 16 and 24 have dropped out of high school (Center for Labor Market Studies 2009). Such youth face high rates of unemployment, poverty, public assistance dependence, criminal involvement, incarceration, and health difficulties, and represent a substantial economic cost to the country through lost wages, taxes and productivity (e.g., Brock 2010; Cohen 1998). Due to the significant individual and societal costs associated with dropping out of school, a range of "second chance programs," have been developed. Such programs have struggled, however, to produce sustained improvements in youth outcomes that endure after programming has ended (Bloom 2010). Retention of outcomes is especially challenging for residential programs, since participants often have difficulty maintaining positive changes once they reenter their communities (Barker 1988).

For more than a decade, the National Guard Youth ChalleNGe Program (NGYCP), an intensive residential program for youth who have dropped out of high school, 
has been implementing an innovative approach to addressing the challenge of retention of outcomes and supporting vulnerable youth in their transition back into their communities: youth-initiated mentoring (YIM). Unlike traditional models of mentoring in which youth are matched with volunteer mentors whom they do not know, under the YIM model, youth nominate mentors from among the non-parental adults who are already part of their social networks (e.g. teachers, family friends, extended family members). The mentors' role is to support youth during and after the completion of the residential phase of the program and, in particular, during the transition back into their communities. Although the specific approach to mentoring used in NGYCP has never been studied, research based on more established approaches to mentoring suggest that this model holds a range of potential benefits. Drawing on quantitative data from a national randomized evaluation of the NGYCP and qualitative data gathered from a subsample of study participants, this study offers the first in-depth examination of YIM relationships and investigates how such relationships may be related to youth outcomes in NGYCP.

\section{Background and Significance}

\section{The NGYCP Model}

NGYCP is a comprehensive program serving youth ages 16-18 years old who have dropped out of high school. It was created in response to relatively disappointing results from a number of programs serving youth who dropped out of school (Bloom 2010). NGYCP consists of a 5-month intensive residential program (frequently on a military base) and a year-long Post-Residential Phase during which participants are supported by a mentor of their choosing. The military setting was thought to provide structure that could benefit youth and reduce the potential negative effects of bringing together high-risk youth (e.g., Dodge et al. 2007), and the setting of the National Guard was chosen for its focus on service to the community. Although the program takes place in a military setting, there are no requirements for military service during or after the program. Results of a national randomized evaluation of NGYCP revealed that, 3 years following random assignment, participants in the treatment group showed significantly improved educational and vocational outcomes (specifically, earning a GED or high school diploma, earning college credit, yearly earnings, and months employed), although no significant differences were detected for behavioral measures (convictions and substance use), and negative effects were detected for physical health (overweight status, although no significant differences were observed for obesity) (Millenky et al. 2011; Millenky et al. 2013).

\section{Theoretical Rationale for YIM}

YIM draws on a growing body of literature suggesting that caring relationships with non-parental adults can contribute to a range of positive youth development outcomes (Sterrett et al. 2011). In particular, YIM represents an innovative and potentially more ecologically valid model of mentoring, a long-standing approach to youth intervention. Youth mentoring, generally defined as a trusting relationship between a young person and an older, nonparental figure who provides guidance and support, has been recognized for its capacity to foster positive behavioral, social-emotional, and academic outcomes (Rhodes 2002). Most mentoring relationships fall into one of two overarching categories: natural mentoring and formal mentoring. Natural mentoring relationships form organically between youth and older individuals (e.g., extended family, teachers, coaches). In formal mentoring, volunteers are matched with youth by an agency, which provides structure and oversight for the relationship.

Although both of these models have advantages, they each carry drawbacks. A major challenge to formal mentoring relationships is the dearth of volunteer mentors, particularly male mentors and mentors of color, resulting in expensive recruiting campaigns and long waitlists (e.g., Rhodes 2002). Moreover, even when youth are assigned mentors, formal mentoring programs tend to achieve relatively small effect sizes overall (e.g., DuBois et al. 2002, 2011). Although formal mentoring relationships can show strong effects when they are close and sustained, such relationships are difficult to achieve. In fact, studies suggest that less than half of formal mentoring relationships last even a full year, and that relationship duration moderates the effects mentoring, with youth in the longest relationships showing the greatest benefits and those in prematurely terminating relationships showing no benefit or even negative impacts from mentoring (Grossman and Rhodes 2002; Grossman et al. 2012). The fragility observed in formal mentoring relationships may stem, in part, from bringing together strangers from potentially very different social contexts (Spencer 2007).

By contrast, natural mentoring relationships, which arise from youth's extant social networks, are more durable, with average relationships lasting almost 9 years (e.g., DuBois and Silverthorn 2005; Zimmerman et al. 2005). Almost half of youth in the United States, however, do not have natural mentors (Zimmerman et al., 2005). Some young people may lack the confidence or social skills to identify and form close relationships with adults in their community (e.g., Georgiou et al. 2008; Zimmerman, et al. 2005). Adult attitudes may 
also contribute to the dearth of naturally forming mentoring relationships. For example, a national survey indicated that only $17 \%$ of adults reported feeling a strong social expectation to get involved with children who are not their own (Scales 2003). Qualitative studies suggest that concern over how other adults will perceive such relationships is a significant barrier to adults assisting other people's children (Mannes and Foster 2004). By providing training and structure for relationships between youth and community members, YIM may have the capacity to redress the shortage of naturally forming mentoring relationships.

YIM also builds on the strengths of natural mentoring relationships by drawing on mentors who are already embedded in youth's social networks, potentially contributing to more enduring relationships. On a practical level, such mentors are more likely to live in the same neighborhoods or communities as the mentees, which facilitates contact. In addition, mentors are likely to be connected to youth in additional capacities (e.g., extended family member, neighbor, teacher), increasing opportunities for spending time together and remaining connected even beyond the time period stipulated in formal mentoring relationships. Mentors drawn from youth's existing social networks also may be more likely to be of similar cultural backgrounds as youth. Formal mentoring programs frequently match low-income youth from minority backgrounds with middle-class, White volunteers (e.g., Tierney and Grossman 1995). Yet research suggests that, when given the choice, youth tend to pick mentors who are of similar backgrounds as themselves (Klaw et al. 2003; Rhodes et al. 1994; Zimmerman et al. 2005), and difficulties bridging cultural differences can contribute to early terminations in formal mentoring relationships (Spencer 2007). Moreover, by providing a structure that encourages and strengthens existing relationships and supports within communities, YIM may foster empowerment and build social capital within communities (Coleman 1988; Rappaport 1981). In fact, research suggests that efforts to build social capital by reinforcing existing social connections are more effective than attempts to create social networks where they do not already exist (Portes and Landolt 2000).

YIM may also allow youth to develop the skills necessary to draw on the support of caring adults in their social networks. Studies indicate that providing training for adolescents in "help-recruiting competencies," that is, teaching adolescents to recruit help from adults, can increase their social support networks and facilitate goal attainment (Balcazar et al. 1991, p. 445). It is possible that the experience gained in YIM, including identifying and approaching a potential mentor and seeking guidance and support from a nonparental adult, could confer valuable interpersonal skills that youth could transfer to other contexts in the future.
Granting autonomy in the process of choosing a mentor may also influence youth's attitudes towards the mentoring relationship. Research on intrinsic motivation suggests that providing choice increases an individual's sense of motivation and investment in a task (e.g., Deci and Ryan 1985). Since youth's perceived lack of motivation and abandonment of the relationship have been shown to be reasons for matches ending prematurely (Spencer 2007), increasing youth's motivation may result in more enduring relationships. YIM may also be a particularly appropriate form of mentoring for adolescents since adolescents tend to show an increased desire for autonomy and independence (e.g., Erikson 1968), and formal mentoring relationships with adolescents tend to be less close (Herrera et al. 2000) and more likely to terminate prematurely (Grossman and Rhodes 2002).

There is reason to believe that YIM holds a range of potential benefits. Moreover, it may be especially appropriate to support NGYCP participants as they transition from a residential program back into their communities. YIM allows participants to elicit the support of someone who is already integrated into their communities, while retaining aspects of the structure provided by formal mentoring. Such support could be critical, and potentially protect against erosion of effects typically observed following participation in residential programs (e.g., Barker 1988). Studies describing the process of reentry into communities following incarceration emphasize the key roles of neighborhood context (Abrams and Snyder 2010), social support (Laub and Sampson 2001), and informal mentoring (Todis et al. 2001) in discouraging recidivism and fostering successful reentry.

At the same time, there are potential drawbacks to the YIM model. While YIM appears to draw on the strengths of natural and formal mentoring relationships, it may be that combining the two types of mentoring has unforeseen shortcomings. For example, it is possible that imposing training and requirements on natural mentoring relationships could interfere with the natural dynamics of the relationships. In addition, the adults who volunteer to participate in formal mentoring programs may represent valuable social capital and connections to which youth may otherwise have little access. In light of these potential benefits and limitations, empirical research is needed to understand the actual experience and impacts of YIM.

\section{Current Study}

The current study explores YIM relationships, employing quantitative data from a national longitudinal evaluation of NGYCP and qualitative data from a subsample of participants in the evaluation. Since YIM represents a new approach to mentoring, we first aimed to characterize the 
mentoring relationships formed under a YIM model. Then, we investigated whether more enduring YIM relationships were associated with greater retention of outcomes among NGYCP participants, and examined match characteristics that predicted more enduring relationships. Specifically, we hypothesized (1) that more enduring mentoring relationships would be associated with improved retention of educational, vocational, and behavioral outcomes 3 years after random assignment, and (2) that mentors selected by youth would be more enduring than those selected by parents or by the program. Qualitative data was used to explore the nature of the relationships and the process through which enduring mentoring relationships may have influenced youth outcomes.

\section{Research Design and Methods}

\section{Participants}

Youth were recruited from 10 NGYCP sites across the country, all of which were identified as having stable staffing and more applicants than available slots (see Millenky et al. 2011). NGYCP is limited to youth ages 16-18 who have dropped out or been expelled from school, are drug-free at the time of entry into the program, not currently on probation or parole for anything beyond juvenile status offenses, not serving time or awaiting sentencing, not under indictment or charged, and not convicted of a felony or capital offense. Demographic information for the 1,173 youth in the study sample is presented in Table 1 . Qualitative data was collected from a subsample of participants in the larger study and included 30 participants from 3 of the 10 sites chosen to represent geographic diversity (namely, California, Michigan, and Mississippi). The participants in the qualitative study were ages 20-22 at the time of the interview. Ninety percent identified as male, and $60 \%$ identified as White, $20 \%$ Latino, $7 \%$ White and Latino, $7 \%$ Black, $3 \%$ White and American Indian, and $3 \%$ unknown.

\section{Intervention}

The ChalleNGe program consists of three phases: the PreChalleNGe Phase, the Residential Phase, and the PostResidential Phase. The Pre-ChalleNGe Phase is a 2-week period of orientation and assessment during which participants adjust to the intensive, highly structured lifestyle required at the program site. The residential phase is a 20-week period during which youth work toward their high school diploma or GED and take classes on life skills, health, and job skills, while participating in other activities such as physical training, sports, leadership and citizenship activities, and community service. The Post-Residential Phase is characterized by a Post-Residential Action Plan in which youth identify specific post-residential activities (e.g., GED program, community college, vocational training, a job, or military service), to be carried out with the support of a mentor.

As part of their application to the ChalleNGe program, youth must nominate one to three potential mentors. Mentors cannot be members of the youth's household or immediate family, and must be at least 21 years old, the same gender as the youth, and live within a reasonable distance from the youth. Nominated mentors are interviewed by program staff to assess their commitment and suitability. Programs also run background checks, obtain references, and provide training for mentors and mentees. Most programs also have a pool of volunteer mentors on which to draw when youth and families are unable to identify a suitable mentor. Mentoring is voluntary, and mentors are not provided with any form of monetary compensation. Matches are formalized during the Residential Phase and expected to last through the Post-Residential Phase. Mentors and mentees are expected to be in contact on a weekly basis during the Post-Residential Phase, with at least two face-to-face meetings per month. ChalleNGe case managers monitor the matches, checking in with mentors on a monthly basis. While formal participation in the program ends after the year-long Post-Residential Phase, some mentoring relationships continue beyond formal program participation.

\section{Procedure}

Youth were recruited for the study through participating ChalleNGe sites. To recruit a total number of 3,074 participants at baseline, random assignment was conducted for 18 program cycles across 10 sites. Applicants signed consent forms to participate in the study and, if they were under 18 years of age, their parents or guardians signed consent forms. Baseline surveys were completed individually by youth when they filled out their program application forms, prior to random assignment. Of the 3,074 participants, 2,320 youth were assigned to the program group and 754 youth were assigned to the control group. Follow up surveys were conducted at approximately 9 months after participants entered the study (i.e., following conclusion of the Residential Phase), 21 months after participants entered the study (i.e., following conclusion of the Post-Residential Phase) and 38 months after participants entered the study (i.e., more than 1.5 years after the conclusion of the Post-Residential Phase). The follow up survey samples were not drawn to represent the full sample surveyed at baseline. Instead, the goal was to obtain a sample that was representative of each of the 10 sites as 
Table 1 Baseline characteristics of youth participants $(N=1,173)$

\begin{tabular}{lllll}
\hline Characteristic $(\%)$ & $\begin{array}{l}\text { Program group } \\
(N=722)\end{array}$ & $\begin{array}{l}\text { Control group } \\
(N=451)\end{array}$ & $\begin{array}{l}\text { Full sample } \\
(N=1,173)\end{array}$ & $\begin{array}{l}\text { Significant difference } \\
\text { between program } \\
\text { and control group }\end{array}$ \\
\hline Male & 87.6 & 88.7 & 88.0 & \\
Age (years) & 16.7 & 16.7 & 16.7 & \\
Race & & & & \\
Hispanic & 19.1 & 16.6 & 18.1 & $*$ \\
White & 42.6 & 42.0 & 42.3 & $*$ \\
Black & 32.4 & 36.0 & 33.8 & \\
Other & 5.9 & 5.4 & 5.7 & \\
On public assistance & 24.2 & 29.6 & 26.4 & \\
Highest grade completed & & & & $*$ \\
8th grade or lower & 12.5 & 17.6 & 14.5 & \\
9th grade & 31.0 & 28.3 & 29.9 & \\
10th grade & 36.6 & 39.9 & 37.9 & \\
11th grade & 19.0 & 14.0 & 17.0 & \\
12th grade & 0.9 & 0.3 & 0.7 & \\
Ever suspended from school & 83.7 & 80.9 & 82.6 & \\
Ever convicted & 20.2 & 14.7 & 18.0 & \\
Ever drink alcohol/use drugs & 39.7 & 34.3 & 37.5 & \\
\hline
\end{tabular}

$\$ p<.10, * p<.05$

well as of the program and control groups. Within these parameters, the subsample was drawn randomly from the full research sample.

Follow-up surveys were conducted by phone or in person by a survey firm. Participants received gift certificates for their participation in each survey. For the 9 month survey, a subsampling of 1,200 youth were targeted, with an $85 \%$ response rate, resulting in a total of 1,018 surveys (see Fig. 1). The 21 month survey was fielded to 1,507 youth (916 in the program group and 592 in the control group), with a $79 \%$ response rate, resulting in a total of 1,196 completed surveys. The 38 month survey targeted the same 1,507 sample members as the 21 month survey, with a response rate of $78 \%$, resulting in a total of 1,173 completed surveys (722 in the program group and 451 in the control group). Table 1 compares selected baseline characteristics of the treatment and control group members who responded to the 38 month survey. Program group respondents had progressed slightly farther in high school at baseline and were less likely to be on public assistance than control group respondents. However, this group was also more likely than the control group to have been convicted and to have used drugs or alcohol at baseline. All of these variables were included as covariates in subsequent analyses comparing the program group to the control group.

In addition to survey data, this study also drew on mentor data from the data management and reporting system (DMARS), a web-based system in which programs recorded data on participants and mentors. Demographic information on mentors was obtained for 1,123 of the study participants (48\% of the participants assigned to the treatment group).

Qualitative interviews were also conducted with a small sampling of participants from the 1,507 youth contacted in the final follow-up survey, with a target of 30 interviews. The survey firm that conducted the 38 month follow-up provided phone numbers for participants. Of the 232 participants in the targeted sites, contact information was functional for only 94 participants, all of whom were invited to take part in the study (by leaving voicemails, leaving messages with household members, or speaking with participants directly), resulting in a total of 30 interviews. Informed consent was obtained in both written and verbal form. Prior to beginning, the purpose and structure of the interviews were described, and participants were given the opportunity to ask questions and informed that they could refuse to answer any questions or stop the interview at any time. All participants were interviewed by telephone, and interviews were audio-recorded and transcribed. Participants received a gift certificate to Walmart. Interviewers used semi-structured protocols, with questions designed to elicit perceptions of the nature, quality, and meaning of the mentoring relationships to youth participants and their influence in youth's lives. Topics in the protocol included how youth chose their mentors, similarities and differences between youth and their mentors, relationship quality and development over time, perceived impact of the relationship, and the role of mentoring in the broader context of the ChalleNGe intervention. Interviewers asked open-ended 


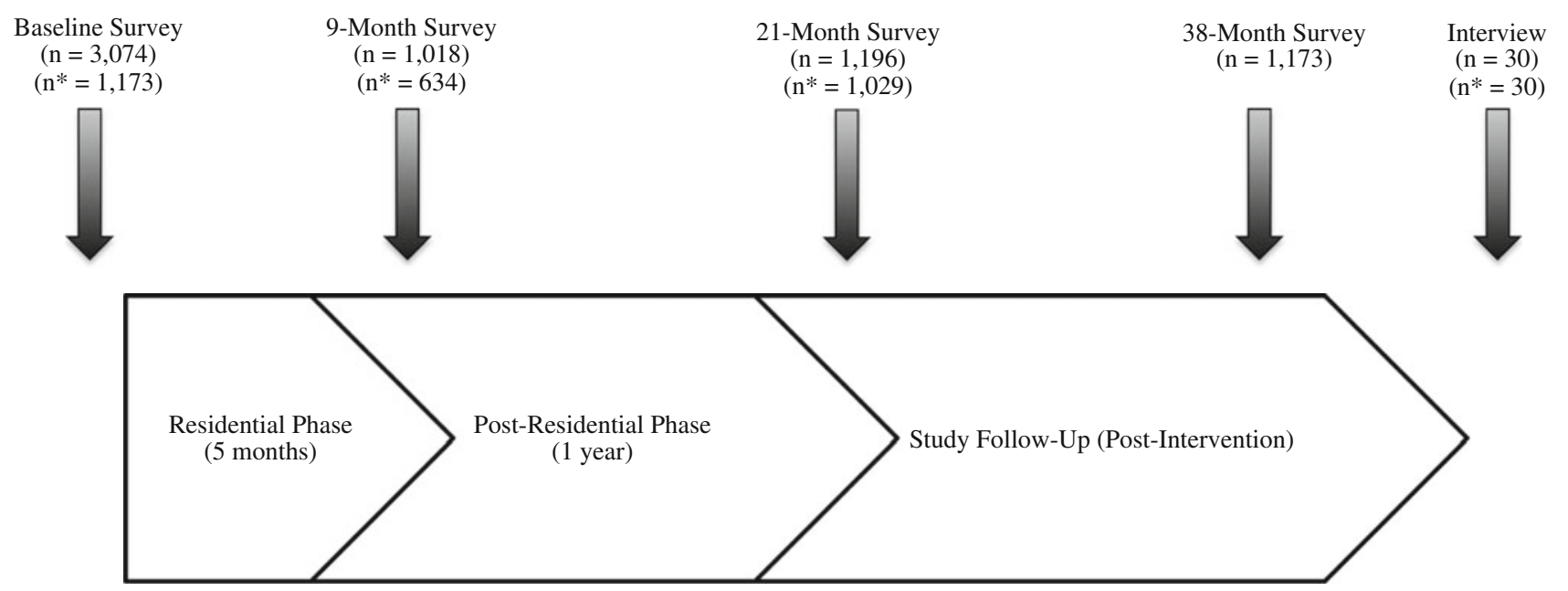

Fig. 1 Flow Chart of Study Participants. $n^{*}=$ Number of participants who were also included in the 38 month follow up survey (i.e., in outcome measures)

questions to draw out experiences and stories from participants, with follow-up questions tailored to participants' individual responses.

\section{Measures}

\section{Baseline Measures of Youth and Mentor Characteristics}

Characteristics of Youth included youths' age, gender, race, zip code, whether anyone in their household was on public assistance, and highest grade completed in school at baseline. Youth also reported whether they had ever been suspended from school, convicted of a crime, and whether they had used drugs or alcohol at baseline.

Characteristics of Mentors included mentors' age, gender, race, zip code, and occupation, based on program records collected through DMARS.

\section{Mentoring Relationship Measures (Measured at Follow Up Surveys)}

Contact with Mentor was measured at all three follow up surveys through youth self-report. At the 9 month survey, youth were asked, on average, how often they met in person with their mentors and how often they talked on the phone. If they responded "never" to both questions, they were considered not to be in contact with their mentors. At the 21 and 38 month surveys, contact was measured through a single question asking youth if they were still in contact with their mentor. At the 21 month survey, youth who endorsed contact with mentors were also asked about the frequency and type of contact (e.g., in person, via phone) in the past 30 days.

Mentor Selection was measured at the 21 month follow up through a question asking youth to choose which response best described how they chose the mentor. Responses included: "You chose your mentor mostly on your own," "Your parents helped you choose," "People from ChalleNGe helped you choose," or "You chose your mentor in some other way."

\section{Outcome Variables (Measured at the 38 month Follow Up)}

This study focused on measures of youth educational, vocational, and behavioral outcomes, encompassing the major objectives of the program. In contrast to the overall evaluation of the program (Millenky et al. 2013), measures of physical health (e.g., obesity) were not included in this study, since the mentoring component did not target physical health.

GED/High School Diploma was measured using two single-item questions asking whether youth had received a high school diploma and whether they had received a GED.

College Credit was measured using a single-item question asking if youth had received any credit towards a college degree.

Employment and Earnings were derived from a series of questions about each job the participant held since random assignment, including the start and end date, hours worked per week, and wages. These measures focus only on employment and earnings in the 12 months prior to the survey interview.

Time Idle was measured using a single-item question asking the number of months since random assignment the participant was "basically not doing anything...not working, not in school, not in a training program, and not in the military." This measure focuses only on the last 12 months prior to the survey interview.

Convictions were measured using a single-item, selfreport question asking youth if they had been convicted since random assignment. 
Binge Drinking was measured using a single-item question asking the number of times in the past 14 days the participant had more than five drinks in a row. Responses were converted into a dichotomous variable representing whether there had been any time in the past 14 days where the participant had more than five drinks in a row. This question was adapted from the Monitoring the Future annual survey (Johnston et al. 2012).

Frequent Marijuana Use was defined as using marijuana on 10 or more occasions in the last 12 months. This question was adapted from the Monitoring the Future annual survey (Johnston et al. 2012).

\section{Data Analysis}

A mixed method explanatory design (Creswell and Clark 2007) was used to investigate our hypothesis that more enduring mentoring relationships would be associated with greater retention of outcomes 3 years following entry into the study. Three analytical techniques were used to explore the quantitative relationship between outcomes and relationship duration. First, ordinary least square (OLS) regressions were used to explore whether variations in duration of mentoring relationships predicted youth outcomes at the 38 months follow up when compared with the control group, while accounting for clustering by site. Individual level covariates measured at baseline included age, gender, racial minority status, public assistance, highest grade completed in school, having been suspended, having been convicted, and use of drugs or alcohol. Dummy variables for each of the 10 NGYCP sites were also created and included as covariates.

If the factors that led to longer matches did not independently also lead to better outcomes, then OLS regressions may provide an unbiased estimate of the impact of match length. However, individuals with longer mentoring relationship may systematically differ at baseline from those with shorter matches. Thus, the regressions were re-estimated using a propensity score matching approach. In particular, we estimated the probability that an individual would have a short, medium or long relationship, as a function of their baseline characteristics. Using the estimates from these regressions, we estimated expected match length based on baseline characteristics for both treatment and control youth. These fitted values were included in the regressions predicting youth outcomes. The coefficients on match length can be interpreted as the impact of having a particular match length conditional on one's expected match length. Thus, using this approach, we were not comparing treatment group youth in longer relationships to the average control group youth, but instead to comparable control group youth.

The third set of analyses employed two-stage least square (2SLS) analyses to investigate if associations observed in the OLS analyses between duration of mentoring relationships and youth outcomes would remain even after potential bias caused by self-selection was removed (Angrist et al. 1996). While the propensity score approach just described compares similar treatment and control youth, it can only equate youth based on baseline characteristics. It is possible, however, that youth in different match lengths systematically differ based on unobservable factors, such as tenacity. To address this possibility, we used the fact that some of the youth who had longer matches would not have had these relationships without being in the experimental group, which is unrelated to the youth's outcomes because youth were randomly assignment into the treatment or control group. We were therefore able to use treatment status as an instrument for match length (see Grossman et al. 2012; Grossman and Rhodes 2002). Since a separate instrument is needed for each variable being instrumented, however, we could use 2SLS analysis to investigate only the impacts on youth in relationships longer than 21 months.

Additionally, we investigated our second hypothesis that relationships in which mentors were selected primarily by youth would be more enduring than those in which mentors were selected by youth's parents or program staff. Using Chi square analysis, within the program group, we examined associations between the method by which mentors were selected (e.g., by youth, by their parents, by program staff) and contact at the 21 and 38 month follow up surveys. We also explored other baseline predictors of match length, using logistic regression to examine whether baseline youth, mentor, or match characteristics could predict contact at the 21 and 38 month surveys within the program group, after controlling for mentors being selected by youth.

Since YIM is a new area of study and may differ from traditional mentoring in the nature of the relationships, qualitative data were collected to further understand the experiences of youth in YIM and the processes through which these relationships influenced youth. The qualitative data served to refine and explain quantitative results by exploring participants' views and experiences in more depth (e.g., Creswell and Clark 2007). In particular, we sought to identify potential themes present within enduring mentoring relationships to understand how those relationships may have influenced youth outcomes. All interviews were transcribed and verified for accuracy. Analysis was conducted using NVivo 9 software according to the guidelines provided by Braun and Clarke (2006) for thematic analysis. First, chunking was employed to identify data related to mentoring relationships, participant outcomes, and baseline participant characteristics. Within the chunked text, initial codes were generated using line-by-line coding to allow for the emergence of themes in each interview (Charmaz 2006). Based on these initial codes, patterns were identified across interviews, and codes were grouped to reflect emerging themes. 
Interviews were then divided into two groups based on match length reported in the quantitative data: (1) enduring mentoring relationships, as defined by those in which youth reported contact at the 21 month follow up (through completion of the Post-Residential Phase) and (2) early terminating relationships, as defined by those in which youth reported that they were not in contact with their mentors at the 21 month follow up. Themes were examined separately among interviews with participants in enduring mentoring relationships versus those in prematurely terminating relationships.

\section{Results}

Characterizing Youth Initiated Mentoring Relationships in NGYCP

\section{Who are the Mentors?}

Program requirements stipulated that all mentors be of the same gender as their mentee. Based on program records, the mean age of mentors was 46.7 years old (standard deviation $=11.0$ ), with the youngest mentor being 26 years old and the oldest mentor being 84 years old. Forty-seven percent of mentors identified as White, $38 \%$ Black, $12 \%$ Latino, $2 \%$ American Indian or Alaskan Native, $1 \%$ Asian or Pacific Islander, and $1 \%$ other. Ninety-three percent of mentors were working full time, $4 \%$ were retired, $3 \%$ were unemployed, and $1 \%$ were working part time. Mentors reported a broad range of occupations, with the most common occupations reported being in management (17\%), education (9\%), protective services $(7 \%)$, construction $(7 \%)$, and social services $(6 \%)$. Based on program records of mentor and mentee racial background, $83 \%$ of mentors were of the same race as their mentees. Twenty-six percent of mentors and mentees lived in neighborhoods with the same zip code. Although quantitative data were not collected on the relationship between mentor and mentee prior to mentor nomination, qualitative data indicated that mentors included family friends, extended family members and godparents, school and extracurricular staff, and religious leaders.

\section{How were Mentors Chosen?}

The majority of participants in mentoring relationships $(55 \%)$ reported that they had chosen their mentors themselves, whereas $37 \%$ of matched youth reported that they were helped by their parents, and $5 \%$ reported they were helped by program staff. The remaining participants (4\%) reported having found their mentors "some other way" (e.g., "he actually asked me to mentor"). Chi square analyses were used to determine whether any demographic variables were associated with participants' method of selecting a mentor. Participants whose families received public assistance at baseline were more likely to select mentors on their own or with the help of program staff and were less likely to receive help from parents in finding a mentor, $\chi^{2}(4,709)=15.19, p<.01$. No significant differences were observed for other baseline variables, including gender, minority status, age, highest grade completed, drug/alcohol use, and suspensions.

\section{Frequency and Duration of Contact Between Mentors and Mentees}

At the 9 month follow-up, $76 \%$ of participants reported contact with mentors. Thirty-four percent of youth reported weekly in-person contact, and $40 \%$ reported weekly phone contact (with $47 \%$ reporting weekly contact of any type). Ten percent of youth reported in-person contact less than once every 4 weeks, and $6 \%$ reported phone contact less than once every 4 weeks. At the 21 month follow up, a similar percentage, $74 \%$, reported contact with their mentors. Contact was slightly less frequent, with only $27 \%$ reporting weekly contact (of any type) and $13 \%$ reporting contact less than once every 4 weeks. By the 38 month follow-up, $56 \%$ of youth reported that they were in contact with their mentor. Due to the similar percentage of youth in contact with their mentors at the 9 and 21 month follow up surveys (76 and $74 \%$, respectively), these groups were combined in subsequent analyses.

There was only one significant difference in baseline youth characteristics based on match length (see Table 2): youth in longer relationships were less likely to have been convicted at baseline. No significant differences emerged for other baseline youth characteristics, including gender, minority status, age, public assistance, highest grade completed, drug/alcohol use, and suspensions.

\section{Youth Outcomes}

After controlling for program site and baseline youth characteristics, participants in the treatment group who were in contact with their mentors at the 38 month followup showed significant benefits compared to the control group on a range of academic, vocational, and behavioral outcomes, including GED/high school diploma, college credit, months employed, earnings, months idle, and convictions (see Table 3). The only outcomes for which no difference was observed between this group and the control group were those related to substance use, namely, binge drinking and frequent marijuana use. Participants in the 
Table 2 Baseline characteristics of participants by match length (treatment group only)

$* p<.05$

${ }^{a}$ Mean values for measure of highest grade completed in school, where $1=8$ th grade or lower; $2=9$ th grade; $3=10$ th grade; $4=11$ th grade;

$5=12$ th grade

\begin{tabular}{lcccc}
\hline & $\begin{array}{l}\text { ML }<21 \text { months } \\
(N=158)\end{array}$ & $\begin{array}{l}\text { ML 21-38 months } \\
(N=138)\end{array}$ & $\begin{array}{l}\text { ML > 38 months } \\
(N=385)\end{array}$ & Significance \\
\hline Male & $129(81.6 \%)$ & $117(84.8 \%)$ & $342(88.8 \%)$ & $\chi^{2}(2,681)=5.26$ \\
Minority status & $81(51.3 \%)$ & $61(44.5 \%)$ & $192(50.1 \%)$ & $\chi^{2}(2,678)=1.60$ \\
Age & $16.73(0.64)$ & $16.74(0.63)$ & $16.74(0.65)$ & $F(2,680)=0.02$ \\
Public assistance & $43(28.1 \%)$ & $35(26.7 \%)$ & $84(23.1 \%)$ & $\chi^{2}(2,647)=1.66$ \\
Highest Grade & $2.62(0.94)$ & $2.74(1.04)$ & $2.65(0.95)$ & $F(2,661)=1.14$ \\
$\quad$ completed $^{\mathrm{a}}$ & $60(39.7 \%)$ & $57(42.5 \%)$ & $145(38.6 \%)$ & $\chi^{2}(2,661)=0.65$ \\
Drug/alcohol use & $128(83.1 \%)$ & $113(84.3 \%)$ & $310(82.2 \%)$ & $\chi^{2}(2,665)=0.32$ \\
Ever suspended & $43(28.7 \%)$ & $28(21.2 \%)$ & $62(16.6 \%)$ & $\chi^{2}(2,655)=9.68^{*}$ \\
Ever convicted & & & &
\end{tabular}

Table 3 Match length as a predictor of outcomes at 38 months (relative to control group) $(N=949)$

\begin{tabular}{|c|c|c|c|c|c|c|c|c|c|}
\hline \multirow[t]{2}{*}{ Outcome } & \multicolumn{3}{|c|}{ ML $<21$ Mos } & \multicolumn{3}{|c|}{ ML 21-38 Mos. } & \multicolumn{3}{|c|}{ ML > 38 Mos. } \\
\hline & $B / O R$ & $S E$ & $95 \% \mathrm{CI}$ & $B / O R$ & $S E$ & $95 \% \mathrm{CI}$ & $B / O R$ & $S E$ & $95 \% \mathrm{CI}$ \\
\hline GED/HS Diploma ${ }^{a}$ & 1.36 & 0.30 & $0.88,2.10$ & $1.83 *$ & 0.44 & $1.14,2.94$ & $2.66^{* *}$ & 0.47 & $1.88,3.75$ \\
\hline College credit ${ }^{\mathrm{a}}$ & 1.26 & 0.29 & $0.80,1.98$ & $1.62 *$ & 0.39 & $1.01,2.61$ & $2.92 * *$ & 0.50 & $2.10,4.08$ \\
\hline Convicted $^{\mathrm{a}}$ & 1.13 & 0.25 & $0.72,1.75$ & 0.71 & 0.18 & $0.43,1.17$ & $0.68^{*}$ & 0.12 & $0.47,0.97$ \\
\hline Binge drinking ${ }^{\mathrm{a}}$ & 0.89 & 0.20 & $0.56,1.39$ & 1.14 & 0.27 & $0.72,1.80$ & 0.88 & 0.15 & $0.62,1.23$ \\
\hline Marijuana use $^{\mathrm{a}}$ & 1.36 & 0.30 & $0.87,2.11$ & 1.07 & 0.26 & $0.66,1.74$ & 0.84 & 0.15 & $0.59,1.19$ \\
\hline Earnings $(\$)^{\mathrm{b}}$ & -39.12 & 1240.14 & $\begin{array}{c}-2469.75 \\
2391.50\end{array}$ & -15.02 & 1240.14 & $\begin{array}{c}-2621.08 \\
2591.03\end{array}$ & $3756.01 * *$ & 938.93 & $\begin{array}{c}1915.74 \\
5596.28\end{array}$ \\
\hline Employed (months) ${ }^{\mathrm{b}}$ & 0.32 & 0.44 & $-0.54,1.17$ & $0.80 \ddagger$ & 0.47 & $-0.12,1.72$ & $1.63 * *$ & 0.33 & $0.98,2.28$ \\
\hline Idle (months) ${ }^{\mathrm{b}}$ & -0.21 & 0.57 & $-1.32,0.90$ & $-2.04 * *$ & 0.61 & $-3.22,-0.85$ & $-2.89 * *$ & 0.43 & $-3.71,-2.07$ \\
\hline
\end{tabular}

$M L$ match length, $S E$ standard error

$\$ p<.10, * p<.05, * * p<.01$

${ }^{a}$ Dichotomous outcome variable; odds ratio (OR) reported. The control group is the reference group

b Continuous outcome variable: B (unstandardized coefficient) reported. The control group is the reference group

treatment group who were in contact with their mentors at the 21 month follow-up but not at the 38 month follow-up showed significant benefits compared to the control group on selected outcomes, including GED/high school diploma, college credit, and months idle. In contrast, participants who were not in contact with their mentors at the 21 month follow up showed no significant differences from the control group on any of the outcome variables examined. The pattern of impacts remained unchanged when we reestimated the effects using a propensity score matching approach (see Table 4). Finally, estimates of the impacts of mentoring relationships lasting longer than 21 months, after controlling for selection bias through the use of 2SLS analyses, also demonstrated significant effects for GED/ high school diploma, college credit, months employed, earnings, months idle, and convictions (see Table 5).

\section{Relationship Processes Within Enduring Mentoring} Relationships

Since quantitative data indicated significant improvements in outcomes among participants in relationships lasting 21 months or longer, qualitative analysis examined themes present in such relationships. Twenty-three of the 30 participants interviewed were in enduring mentoring relationships (as defined by being in contact with mentors at the 21 month follow up). Qualitative data from these participants supported quantitative findings, indicating that enduring mentoring relationships could positively influence participant outcomes. Participants in enduring relationships described how mentors supported their success within the ChalleNGe program, as well as how mentors supported their positive development more generally in their lives. 
Table 4 Match length as a predictor of outcomes at 38 months (relative to control group) with propensity matching $(N=845)$

\begin{tabular}{|c|c|c|c|c|c|c|c|c|c|}
\hline \multirow[t]{2}{*}{ Outcome } & \multicolumn{3}{|c|}{ ML $<21$ Mos. } & \multicolumn{3}{|c|}{ ML 21-38 Mos. } & \multicolumn{3}{|c|}{ ML > 38 Mos. } \\
\hline & $B / O R$ & $S E$ & $95 \% \mathrm{CI}$ & $B / O R$ & $S E$ & $95 \% \mathrm{CI}$ & $B / O R$ & $S E$ & $95 \% \mathrm{CI}$ \\
\hline GED/HS Diploma ${ }^{a}$ & 1.45 & 0.36 & $0.89,2.35$ & $1.91 *$ & 0.49 & $1.15,3.17$ & $3.11 * *$ & 0.60 & $2.13,4.52$ \\
\hline College Credit ${ }^{\mathrm{a}}$ & 1.10 & 0.28 & $0.67,1.83$ & $1.68 *$ & 0.44 & $1.01,2.82$ & $3.41 * *$ & 0.63 & $2.38,4.89$ \\
\hline Convicted $^{\mathrm{a}}$ & 1.11 & 0.27 & $0.68,1.80$ & $0.62 \ddagger$ & 0.17 & $0.36,1.07$ & $0.63 *$ & 0.12 & $0.43,0.93$ \\
\hline Binge Drinking ${ }^{\mathrm{a}}$ & 0.94 & 0.23 & $0.58,1.53$ & 1.00 & 0.25 & $0.61,1.64$ & 0.97 & 0.18 & $0.68,1.39$ \\
\hline Marijuana Use ${ }^{a}$ & 1.48 & 0.36 & $0.91,2.39$ & 1.14 & 0.30 & $0.68,1.90$ & 0.87 & 0.17 & $0.60,1.28$ \\
\hline Earnings $(\$)^{\mathrm{b}}$ & -1369.41 & 1360.23 & $-403541,1296.59$ & -728.34 & 1428.65 & $-3528.44,2071.75$ & $3123.99 * *$ & 1008.69 & $1147.00,5100.97$ \\
\hline Employed (months) ${ }^{\mathrm{b}}$ & 0.21 & 0.48 & $-0.91,0.95$ & 0.56 & 0.50 & $-0.42,1.54$ & $1.51 * *$ & 0.35 & $0.82,2.20$ \\
\hline Idle (months) ${ }^{\mathrm{b}}$ & 0.12 & 0.63 & $-1.11,1.35$ & $-2.10 * *$ & 0.66 & $-3.39,-0.81$ & $-3.22 * *$ & 0.46 & $-4.13,-2.31$ \\
\hline
\end{tabular}

$M L$ match length, $S E$ standard error

* $p<.10, * p<.05, * * p<.01$

${ }^{a}$ Dichotomous outcome variable; odds ratio (OR) reported. The control group is the reference group

${ }^{\mathrm{b}}$ Continuous outcome variable: B (unstandardized coefficient) reported. The control group is the reference group

Table 5 OLS and 2SLS regression estimates of impacts on participants in relationships lasting 21 months or longer $(N=979)$

\begin{tabular}{|c|c|c|c|c|c|c|}
\hline \multirow[t]{2}{*}{ Outcome } & \multicolumn{3}{|c|}{ Ordinary least square regression } & \multicolumn{3}{|c|}{ Two stage least square regression } \\
\hline & $B$ & $R S E$ & $95 \% \mathrm{CI}$ & $B$ & $R S E$ & $95 \% \mathrm{CI}$ \\
\hline GED/HS Diploma & $0.17 * *$ & 0.03 & $0.11,0.22$ & $0.22 * *$ & 0.04 & $0.14,0.29$ \\
\hline College credit & $0.17 * *$ & 0.02 & $0.13,0.22$ & $0.22 * *$ & 0.04 & $0.15,0.29$ \\
\hline Convicted & $-0.06^{*}$ & 0.03 & $-0.12,-0.01$ & $-0.06 \ddagger$ & 0.03 & $-0.13,0.08$ \\
\hline Binge drinking & -0.01 & 0.03 & $-0.07,0.04$ & -0.06 & 0.04 & $-0.13,0.01$ \\
\hline Marijuana use & -0.02 & 0.03 & $-0.07,0.03$ & -0.01 & 0.03 & $-0.08,0.06$ \\
\hline Earnings (\$) & $2781.65 * *$ & 892.46 & $1032.46,4530.84$ & $3356.20 * *$ & 1016.75 & $1363.41,5349.00$ \\
\hline Employed (months) & $1.41 * *$ & 0.23 & $0.96,1.87$ & $1.62 * *$ & 0.36 & $0.91,2.34$ \\
\hline Idle (months) & $-2.62 * *$ & 0.27 & $-3.14,-2.10$ & $-2.71 * *$ & 0.49 & $-3.68,-1.75$ \\
\hline
\end{tabular}

All regressions compare the outcomes of participants in the treatment group whose mentoring relationships lasted at least 21 months to the outcomes of all other participants (including those in the control group and those in the treatment group who were no longer in contact with their mentors at the 21 month follow up)

$M L$ match length; RSE robust standard error

$\$ p<.10, * p<.05, * * p<.01$

\section{Supporting Program Success}

Although the mentoring component was designed primarily to support youth during the Post-Residential Phase, an unexpected theme that emerged from interview data was the role that mentors played during the Residential Phase of the program. In fact, all but 1 participant described benefiting from their mentor's support during the Residential Phase of the program. Due to the intensity of the Residential Phase and the fact that most sites allowed youth little communication with people outside the program besides their mentors, mentors took on a particularly important role during this phase. One participant stated, "I'm convinced that's the whole reason I got through the program, was because of my mentor." Another described a time he wanted to drop out of the program, but a phone call with mentor persuaded him to stay, explaining, "We had like a, a really long talk about, about why I needed to stay there, and how like, what I needed to do in order to, to stay there, and...that was like the turning point that made me decide that I was gonna like keep trying when I was at the camp."

Participants also described the importance of mentors during the Post-Residential Phase. One participant observed that, without the mentoring component, "It would've been cool, like the whole program an' everything, but not having a plan for afterwards, or someone you can go talk to, you probably would'a' just went back to the same, you know, same stuff you were doing...It probably only would'a' changed you for the 6 months you were in 
there, an' then you would'a' went right back, like afterwards." Thus, mentors played an important role in participants' success in the program, both during the Residential Phase, encouraging participants to persevere in the challenging residential program, as well as during the PostResidential Phase, helping participants maintain changes they achieved during the Residential Phase.

\section{Supporting Positive Development}

In addition to helping youth to be successful in the context of the program, participants also described how mentors supported their positive development in general. Among participants in enduring mentoring relationships, three major themes emerged related types of support they received: (1) social-emotional support, (2) guidance, and (3) instrumental support.

Social-Emotional Support The most common theme among interviews with participants in enduring mentoring relationships was the social-emotional support they received from mentors. Participants described mentors as "somebody to rely on," and "somebody who cared about me." Some participants reported that this support changed the way they viewed themselves. One participant observed, "I guess you could say he showed me the potential that I could have." For other participants, relationships with their mentors influenced their approach to relationships in general and their ability to trust people, resulting in improved relationships with family members and others. One participant explained, "[My mentoring relationship] made me a better person. Because out of the respect I had for him, helped me to respect other people...And that was a big step for me, because I went through a lot, and everybody, it felt like everybody was stabbin' me in my back, and then he came along and he was, he was more than a mentor, he was a friend." Overall, participants in enduring mentoring relationships reported benefiting from the support of a caring and dependable adult. For some, this relationship changed the way they viewed themselves and others, resulting in improved self-concept and relationships with others.

Guidance Another common theme that emerged in interviews was receiving guidance from mentors, and feeling comfortable turning to mentors for advice "whenever I have a question about anything...no matter what it is." Participants described how mentors' advice generally helped them to "stay on track," "guide me in the right direction," and "give you that jump start." Much advice was focused on refraining from engaging in problem behavior and staying out of trouble. For example, one participant described meeting with his mentor, saying, "...if I had felt like I had made mistakes, he wanted to know if you know, he could help me with anything, or if I was slippin' back into the old life, that kinda stuff." Other participants described how mentors' advice motivated them to pursue educational and vocational goals and, in some cases, how their mentors helped them to obtain information about applying to college or taught them skills they needed for job interviews. One participant explained, “...I went to a community college at first, and [my mentor] wanted to make sure that I didn't stop there, she wanted to make sure that I pursue my career, she wanted to make sure that I wasn't gonna be pregnant or you know, on drugs, and um, I haven't, I haven't let her down on any of that." Some participants also described mentors influencing goals related to marriage and family. One participant stated that his mentor "showed me where I'd like to be one day, you know, um, steady home, uh, children, a wife." In sum, participants in enduring mentoring relationships described receiving guidance from mentors across a broad range of areas and believed that this advice helped them to stay on track, keep out of trouble, and move towards educational, career, and family goals.

Instrumental Support A final way in which some mentors supported their mentees was by being available to provide practical assistance, such as helping them find jobs, letting them borrow a car, or advocating on their behalf in court. Moreover, this instrumental support also contributed to participants' sense of emotional support when they saw that their mentors were willing to go out of their way to provide assistance. One participant explained that, although his mentor had helped him in many ways, "the biggest one was when he got me a job, like actually took time out of his day to like call a buncha people an' get me hired on that day." Another participant described how his mentor came to court with him after he was arrested to advocate on his behalf, observing, "He was there looking out for me and making sure that I was not going to jail and stuff like that." Overall, along with emotional support and guidance, some participants described benefiting from practical assistance from their mentors.

\section{Relationship Processes Within Early Terminating Mentoring Relationships}

Analysis of interviews with participants in shorter mentoring relationships (specifically, the 6 participants interviewed who were not in contact with mentors at the 21 month follow up) revealed that they received more limited support than those in longer relationships. Nevertheless, most participants who were in contact with their mentors even during part of the Residential Phase reported that this contact was helpful, with one participant even noting that his mentor persuaded him to stay in the program when he wanted to drop out. In contrast, a participant whose mentor never showed up to visit during the 
Residential Phase reported feeling "really upset," and described missing the mentor contact that he perceived as "a little piece of home."

Some participants also described feeling disappointed that they did not receive more support during the postresidential phase. One participant reported, "I guess I was hoping that she would be there more than she was... and, and she wasn't, and my mom was expectin' the same thing, an' she wasn't." She attributed her mentor's absence partly due to the fact that "she was always workin'," but also because her mother and her mentor had worked together, and "whenever my mom had quit that job or whatever, I guess she just went her separate way, and didn't come around anymore."

Interviews with participants in shorter relationships revealed that those who were in contact during the Residential Phase valued the support they received, although some wished the relationships would have lasted longer. These interviews also provided insight into potential risks of YIM relationships, namely, that mentors may be too busy to carry out mentoring responsibilities, or that changes in relationships outside the mentoring relationship (e.g., relationships with participants' parents) could negatively influence mentoring relationships.

\section{Predictors of Match Length}

As hypothesized, the process by which mentors were selected significantly predicted contact at the 21 month follow up, $\chi^{2}(3,655)=23.0, p<.01$, and at the 38 month follow up $\chi^{2}(3,655)=13.1, p<.01$. Specifically, $81.4 \%$ of those who selected mentors "mostly on [their] own" reported contact with their mentors at the 21 month follow up, in comparison with $71.1 \%$ for those whose parents helped select their mentors, and $52.8 \%$ for those helped by ChalleNGe staff. At the 38 month follow up, although fewer participants were in contact with the mentors overall, youth who selected mentors on their own were most likely to be in contact $(59.2 \%)$, compared with $48.1 \%$ for mentors selected by parents, and $36.1 \%$ for those selected by staff.

In addition, when other youth, mentor, and match characteristics were included in the model, selection of mentors by youth remained significant (odds ratio $=1.99$, $p<.05$ ), and youth and mentors who were of the same racial background were also significantly more likely to be in contact at the 21 month follow up (odds ratio $=3.28$, $p<.01)$. None of the other baseline youth characteristics (including gender, age, race, public assistance, highest grade completed, suspension, conviction, or drug/alcohol use) or baseline mentor or match characteristics (including age, social status, or living in the same zip code area as mentees) significantly predicted contact at the 21 month follow up. Similarly, at the 38 month follow up, selection of mentors by youth remained significant (odds ratio $=1.82, p<.05$ ), and mentors and youth who were of the same race were more likely to be in contact (odds ratio $=3.44, p<.01)$. No other baseline characteristics significantly predicted contact at the 38 month follow up.

Interview data provided more insight into the way in which mentor and youth characteristics influenced match length and relationship quality. The majority of participants reported having similar backgrounds to their mentors and most described similarities in culture, ethnicity, and race as beneficial to their mentoring relationships. A White male participant described his mentor saying, "We were both raised in the church, both military raised...Everything that we believed in was just about the same...it was one of the main reasons I highly considered him to be my mentor, and that's why he's still my mentor 'til this day." A Latina female participant explained, "Well, being a Latino...it really did help, the fact that she was the same race as me...if she was a different race than I was, maybe she wouldn't understand why I was struggling so much, not getting along with my dad, or how important it was for me to get along with my dad." A Black male participant reported that it was important for him that his mentor was a successful Black man, noting, "Just to see a, a, a Black man just, in our community, that just basically came up, 'cause 'round here mostly don't see too many like that...makin', makin' money the right way." In sum, the majority of participants in enduring relationships reported having similar backgrounds to their mentors, and most of them believed that these similarities were beneficial to the relationship.

\section{Discussion}

Results from this study indicated that enduring YIM mentoring relationships were associated with greater retention of outcomes among participants in NGYCP. Participants in contact with their mentors at the 38 month follow up showed significantly more positive impacts relative to the control group on all outcome variables examined (GED/ high school diploma, college credit, months employed, earnings, months idle, and convictions), with the exception of substance use (binge drinking and frequent marijuana use). Significant impacts were also observed among participants in contact with their mentors at the 21 month follow up but not at the 38 month follow up, although for a smaller number of outcomes variables (significant improvements for GED/high school diploma, college credit, and months idle). In contrast, those who were no longer in contact with their mentors at the 21 month follow up showed no significant positive impacts relative to the 
control group. Even when potential selection bias was controlled for, results indicated that mentoring relationships lasting at least 21 months led to improved youth outcomes. These results indicate that enduring YIM relationships can contribute to the maintenance and development of positive outcomes among participants in NGYCP.

This study also provides the first characterization of YIM relationships. Results revealed that the majority of YIM relationships in NGYCP were relatively long-lasting, with $74 \%$ of participants reporting contact with their mentors at the 21 month follow up, and $56 \%$ reporting contact at the 38 month follow up. This is substantially longer than traditional formal mentoring relationships in which less than half of relationships last even 1 year (Grossman and Rhodes 2002). Although it is possible that YIM relationships in the context of NGYCP are particularly enduring, it also may be that by drawing on adults already embedded in youth's communities, the YIM model is especially conducive to enduring relationships. At the same time, results indicated that only $47 \%$ of youth reported weekly contact at the 9 month follow up and only $27 \%$ at the 21 month follow up, suggesting that imposing a structure of weekly meetings on YIM relationships may be challenging. Nevertheless, since relationships lasting at least 21 months were effective, it may be less important how frequently they meet but rather that they are still in contact. It is also possible that mentors who are nominated by youth have less time available than those who volunteer to be mentors. In fact, among mentors nationally, only $32 \%$ work full time (MENTOR 2006), whereas, in the NGYCP sample of mentors, $93 \%$ worked full time.

As hypothesized, youth who chose mentors mostly on their own were more likely to be in enduring relationships than those who received help choosing their mentors from parents or staff. This may reflect that youth can best gauge who would be a good match for them, as well as the possibility that choosing their mentors themselves caused youth to be more invested in the relationship (Deci and Ryan 1985). At the same time, it is also likely that youth who were able to identify a mentor on their own had better relationship skills at baseline, allowing them to more successfully sustain relationships.

Results also indicated that mentors and mentees who were of the same race tended to be in longer-lasting relationships. These findings differ from research on formal mentoring relationships which, for the most part, have not observed significant differences in relationship duration or quality between same race versus cross race matches (Herrera et al. 2000; Rhodes et al. 2003). They are consistent, however, with research indicating that difficulty bridging cultural differences can be a cause for early termination of relationships (Spencer 2007), as well as a study of natural mentors among African American mothers, which found that all mentors in enduring relationships were of the same race as their mentees (Klaw et al. 2003).

Qualitative data also shed light on the mechanisms through which enduring mentoring relationships fostered positive youth outcomes. Interviews indicated that mentors provided valuable social-emotional support, guidance, and instrumental support that contributed to improvement in participants' educational and occupational success, relationships, and self-concept. These results support other research indicating that the provision of various types of social support may explain associations between positive youth development outcomes and relationships with nonparental adults (e.g., Sterrett et al. 2011). The interviews also revealed the role of mentors in supporting participants' success in NGYCP, both during the Residential and PostResidential Phase, suggesting that YIM may be a particularly effective strategy to incorporate into residential programs, both to help participants complete the program and to help them maintain their gains after the program ends.

Although further research is needed to investigate the impacts of YIM, this study suggests that YIM may be an effective model of mentoring for vulnerable adolescents. These results have important implications for youth mentoring. On a practical level, YIM could reduce the cost of recruiting volunteers and serve as a strategy for redressing the dearth of volunteer mentors. In addition, results suggest that YIM relationships may help to address the problem of prematurely terminating relationships. Moreover, the YIM model allows communities to recognize, harness, and develop the internal social capital and cultural wealth available to youth within their communities (Portes and Landolt 2000; Yosso 2005).

The results of this study also indicate that YIM may be a particularly effective strategy to address the challenge of erosion of outcomes in prevention and treatment programs, particularly for residential programs. YIM may be able to extend the influence of residential programs by providing youth with a mentor from their community who can help them maintain behaviors learned during the residential period and follow through in pursuing their goals, as well as helping them to get back on track if they begin to regress. In addition, qualitative data suggest that mentors not only can support youth during the Post-Residential Phase and beyond, but they also can play an important role in helping youth to successfully complete the residential program. As such, YIM may be a particularly promising strategy to incorporate into existing intervention programs to bolster program success and attenuate the erosion of gains.

This study provides an important contribution to the mentoring literature as one of the first examinations of YIM relationships to date. Nevertheless, it has significant limitations that should be noted. First, this study 
investigated YIM in the context of NGYCP, which is a unique and intensive intervention serving a particularly high-risk population of adolescents. As such, findings may not generalize to YIM as a stand alone intervention or in the context of other intervention programs. Similarly, since YIM was one component of the larger NGYCP intervention, it is difficult to separate the impacts of YIM from the impacts of the overall intervention. In addition, although relationships in which youth chose their mentors were more enduring than those in which parents or staff played a role, these conditions were not random. Future experimental studies that randomly assign participants to YIM versus traditional assigned mentoring conditions will be necessary to draw causal conclusions about the relative merits of YIM. Furthermore, while the study was strengthened by the inclusion of qualitative data, interviews were limited to those who could be contacted and agreed to be interviewed, which may have biased results.

Despite these limitations, the results of this study serve to call attention to a promising new approach to mentoring that holds significant potential as a strategy to support vulnerable adolescents, redress challenges associated with traditional mentoring, attenuate erosion of effects for residential programs, and mobilize and strengthen internal social capital in communities.

Acknowledgments The authors gratefully acknowledge Megan Millenky, Dan Bloom, and other members of the ChalleNGe evaluation team, David Van Patten, and the generous support of Dare Mighty Things, MacArthur Foundation, Bill \& Melinda Gates Foundation, Charles Stewart Mott Foundation, Edna McConnell Clark Foundation, MCJ Foundation, Robert Wood Johnson Foundation, William and Flora Hewlett Foundation and the U.S. Department of Defense.

\section{References}

Abrams, L. S., \& Snyder, S. M. (2010). Youth offender reentry: Models for intervention and directions for future inquiry. Children and Youth Services Review, 32, 1787-1795.

Angrist, J., Imbens, G., \& Rubin, D. (1996). Identification of causal effects with instrumental variables. Journal of the American Statistical Association, 91, 444-455.

Balcazar, F. E., Majors, R., Blanchard, K. A., Fawcett, S. B., Paine, A., Suarez-Balcazar, Y., et al. (1991). Teaching minority high school students to recruit helpers to attain personal and educational goals. Journal of Behavioral Education, 1, 445-454.

Barker, P. (1988). The future of residential treatment for children. In C. Schaefer \& A. Swanson (Eds.), Children in residential care: Critical issues in treatment (pp. 1-16). New York: Van Nostrand Reinhold.

Bloom, D. (2010). Programs and policies to assist high school dropouts in the transition to adulthood. The Future of Children, 20, 89-108.

Braun, V., \& Clarke, V. (2006). Using thematic analysis in psychology. Qualitative Research in Psychology, 3, 77-101.

Brock, T. (2010). Young adults and higher education: Barriers and breakthroughs to success. The Future of Children, 20, 109-132.
Center for Labor Market Studies. (2009). Left behind in America: The nation's dropout crisis. Boston: Northeastern University. Retrieved from http://hdl.handle.net/2047/d20000598.

Charmaz, K. (2006). Constructing grounded theory: A practical guide through qualitative analysis. Thousand Oaks, CA: Sage Publications.

Cohen, M. A. (1998). The monetary value of saving a high-risk youth. Journal of Quantitative Criminology, 14, 5-33.

Coleman, J. (1988). Social capital in the creation of human capital. The American Journal of Sociology, 94, 95-120.

Creswell, J. W., \& Clark, V. (2007). Designing and conducting mixed methods research. Thousand Oaks, CA: Sage Publications.

Deci, E. L., \& Ryan, R. M. (1985). Intrinsic motivation and selfdetermination in human behavior. New York: Plenum.

Dodge, K. A., Dishion, T. J., \& Lansford, J. E. (Eds.). (2007). Deviant peer influences in programs for youth: Problems and solutions. New York: Guilford Press.

DuBois, D. L., Holloway, B. E., Valentine, J. C., \& Cooper, H. (2002). Effectiveness of mentoring programs for youth: A metaanalytic review. American Journal of Community Psychology, 30, 157-197.

DuBois, D. L., Portillo, N., Rhodes, J. E., Silverthorn, N., \& Valentine, J. C. (2011). How effective are mentoring programs for youth? A systematic assessment of the evidence. Psychological Science in the Public Interest, 12, 57-91.

DuBois, D. L., \& Silverthorn, N. (2005). Characteristics of natural mentoring relationships and adolescent adjustment: Evidence from a national study. The Journal of Primary Prevention, 26, 69-92.

Erikson, E. H. (1968). Identity: Youth and Crisis. New York: Norton.

Georgiou, S. N., Demetriou, A. P., \& Stavrinides, P. (2008). Attachment style and mentoring relationships in adolescence. Educational Psychology, 28, 603-614.

Grossman, J. B., Chan, C., Schwartz, S. E. O., \& Rhodes, J. E. (2012). The test of time in school-based mentoring: The role of relationship duration and re-matching on academic outcomes. American Journal of Community Psychology, 49, 43-54.

Grossman, J. B., \& Rhodes, J. E. (2002). The test of time: Predictors and effects of duration in youth mentoring programs. American Journal of Community Psychology, 30, 199-206.

Herrera, C., Sipe, C., \& McClanahan, W. (2000). Mentoring schoolage children: Relationship development in community-based and school-based programs. Philadelphia: Public/Private Ventures.

Johnston, L. D., O’Malley, P. M., Bachman, J. G., \& Schulenberg, J. E. (2012). Monitoring the Future national results on adolescent drug use: Overview of key findings 2011. Ann Arbor: Institute for Social Research, The University of Michigan.

Klaw, E. L., Rhodes, J. E., \& Fitzgerald, L. F. (2003). Natural mentors in the lives of African American adolescent mothers: Tracking relationships over time. Journal of Youth and Adolescence, 32, 223-232.

Laub, J. H., \& Sampson, R. J. (2001). Understanding desistance from crime. Crime and Justice: A Review of Research, 28, 1-69.

Mannes, M., \& Foster, K. (2004). Cultivating human development for young Kansans: How people, places, and permission are making it happen. Minneapolis: Search Institute.

MENTOR/National Mentoring Partnership. (2006). Mentoring in America 2005: A snapshot of the current state of mentoring. Alexandria, VA: Author.

Millenky, M., Bloom, D., Muller-Ravett, S., \& Broadus, J. (2011). Staying on course: Three-year results of the National Guard Youth ChalleNGe evaluation. New York: MDRC.

Millenky, M., Schwartz, S. E. O., \& Rhodes, J. E. (2013). Supporting the transition to adulthood among high school dropouts: An impact study of the National Guard Youth ChalleNGe Program. Prevention Science. doi:10.1007/s11121-013-0388-4. 
Portes, A., \& Landolt, P. (2000). Social capital: Promises and pitfalls of its role in development. Journal of Latin American Studies, $32,526-547$.

Rappaport, J. (1981). In praise of paradox: A social policy of empowerment over prevention. American Journal of Community Psychology, 9, 1-25.

Rhodes, J. (2002). Stand by Me: The risks and rewards of mentoring today's youth. Cambridge, MA: Harvard University Press.

Rhodes, J., Contreras, J., \& Mangelsdorf, S. (1994). Natural mentors' relationships among Latino adolescent mothers: Psychological adjustment, moderating processes, and the role of early parental acceptance. American Journal of Community Psychology, 22, 211-228.

Rhodes, J., Reddy, R., Grossman, J., \& Lee, J. (2003). Same- versus cross-race matches in mentoring programs: A comparison. Journal of Applied Social Psychology, 32, 2114-2133.

Scales, P. (2003). Other people's kids: Social expectations and American adults' involvement with children and adolescents. New York: Kluwer Academic/Plenum Publishers.

Spencer, R. (2007). "It's not what I expected": A qualitative study of youth mentoring relationship failures. Journal of Adolescent Research, 22, 331-354.
Sterrett, E. M., Jones, D. J., McKee, L. G., \& Kincaid, C. (2011). Supportive non-parental adults and adolescent psychosocial functioning: Using social support as a theoretical framework. American Journal of Community Psychology, 48, 284-295.

Tierney, J. B., \& Grossman, J. B. (1995). Making a difference: An impact study of big brothers big sisters. Philadelphia, PA: Public/Private Ventures.

Todis, B., Bullis, M., Waintrup, M., Schultz, R., \& D'Ambrosio, R. (2001). Overcoming the odds: Qualitative examination of resilience among formerly incarcerated adolescents. Exceptional Children, 68, 119-139.

Yosso, T. J. (2005). Whose culture has capital? A critical race theory discussion of community cultural wealth. Race Ethnicity and Education, 8, 69-91.

Zimmerman, M. A., Bingenheimer, J. B., \& Behrendt, D. E. (2005). Natural mentoring relationships. In D. L. Dubois \& M. L. Karcher (Eds.), Handbook of youth mentoring (pp. 143-159). Thousand Oaks, CA: Sage Publications, Inc. 